\title{
Abordagens em epistemologia: Bachelard, Morin e a epistemologia da complexidade ${ }^{1}$
}

\author{
Approaches to epistemology: Bachelard, Morin and the \\ epistemology of complexity
}

Marivalde Moacir FRANCELIN²

RE S U M O

Apresenta uma revisão das distintas concepções de epistemologia, partindo da epistemologia enquanto palavra. Em seguida, aborda sua estrutura enquanto campo de investigação e disciplina do conhecimento, chegando ao seu desdobramento em epistemologias. Argumenta que a epistemologia da complexidade comporta, e é comportada, por essas epistemologias. Procura reconstituir um itinerário móvel e flexível da epistemologia até sua relação com a complexidade a partir de Gaston Bachelard e Edgar Morin.

Palavras-chave: epistemologia, epistemologia da complexidade, Gaston Bachelard, Edgar Morin, perspectivismo.

\section{A B S T R A C T}

This article presents a review of the distinct conceptions of epistemology, departing from the concept of epistemology as a word. It approaches the structure of epistemology, taken as both, a research field and the discipline of knowledge, and considers its developments into plural epistemologies. Furthermore, the author argues that the epistemology of complexity circumscribes, and is itself

\footnotetext{
1 Texto elaborado a partir de uma das seções da dissertação de mestrado defendida pelo autor em 2004.

2 Mestre em Biblioteconomia e Ciência da Informação, Pontifícia Universidade Católica de Campinas. Docente, Curso Ciência da Infomração com Habilitação emn Biblioteconomia, Faculdade de Biblioteconomia, Centro de Ciências Sociais Aplicadas, Pontifícia Universidade Católica de Campinas. Rua Marechal Deodoro, 1099, Centro, 13020-904, Campinas, SP, Brasil.E-mail: <mfrancelin@yahoo.com.br>

Recebido em 22/2/2005 e aceito para publicação em 19/5/2005.
} 
circumscribed, by such epistemologies. In short, the article aims to establish a mobile and flexible itinerary regarding epistemology, up to its relationship with the complexity, as posed by the works of Gaston Bachelard and Edgar Morin.

Key words: epistemology, epistemology of complexity, Gaston Bachelard, Edgar Morin, perspectivism.

\section{N T R O D U ÇÃ O}

Discutir o que venha a ser ou se tornar epistemologia está longe de qualquer tipo de facilidade aparente. Suas ramificações e conceitos, além de uma etimologia que remonta aos gregos, parecem imprimir maior grau de dificuldade no trato com o tema. Porém, pode ser essa mesma dificuldade um dos principais incentivos para se tentar revigorar a discussão em torno da epistemologia. Diante de uma vertente clássica e, aparentemente, ultrapassada, surgem distinções em seus aspectos conceituais, teóricos e metodológicos, possibilitando o desenvolvimento de epistemologias.

Portanto, as reflexões a seguir não procuram eleger a melhor epistemologia, mas proporcionar subsídios para novas discussões em torno do caráter complexo das epistemologias que, na contemporaneidade, revigoramse sob a égide de um espírito científico transformado e em transformação. Inicialmente, procurou-se abordar a epistemologia como epistemologia e não como episteme, ou seja, a epistemologia em seu sentido científico e disciplinar. Isto implica uma breve menção às suas origens e etimologia e uma discussão sobre sua emergência, características e objetivos, sem a pretensão de se esgotar o assunto e, muito menos, de se tomar como conclusão uma epistemologia melhor. Objetiva-se sim, discutir uma epistemologia que possa dar respostas e que, mesmo não as dando, possa contemplar uma ciência em expansão interdisciplinar e metodológica. A discussão, já bem avançada, da interdisciplinaridade nas disciplinas científicas contemporâneas, acaba por apontar para uma outra discussão, a discussão episte- mológica. Pode-se dizer que a própria epistemologia, enquanto disciplina, comporta, ao longo de seu desenvolvimento um caráter interdisciplinar direcionando-se para a complexidade. Como termo, a epistemologia parece ser muito utilizada no cotidiano científico, mas, como disciplina ou como uma metodologia de análise, necessita de maiores estudos. Por isso e pelo seu conceito inexato procura-se recorrer, com certa constância, aos estudiosos e pesquisadores deste campo. Talvez não seja possível traçar um "itinerário" sobre a epistemologia sem sobrecarregá-lo de citações, procurando evidenciar que este "itinerário" não seguiu uma rota préestabelecida e única, mas conturbada, ruidosa e, por vezes, sutil. Esse é o panorama do segundo item de discussão deste texto Abordagens em epistemologia.

O item três, Bachelard, Morin e a epistemologia da complexidade, procura identificar, a partir da própria proposta de Edgar Morin, as estruturas constitutivas da epistemologia da complexidade, partindo de Gaston Bachelard. Neste caso, discute-se um novo conceito de epistemologia complexa, que não parece ser tão novo assim, ou seja, o foco é sobre a discussão de um campo de estudo e de uma atuação metodológica já constituídos e, aparentemente, presente em boa parte das disciplinas científicas contemporâneas. Assim, entende-se que o item dois, Abordagens em epistemologia, além de panorâmico e reflexivo (nos dois sentidos do termo), é perspectivista (não no sentido filosófico, mas no sentido de lançar bases) em relação ao item três, Bachelard, Morin e a epistemologia da complexidade, por seu fundamento distintivo e variado. O processo de criarnunca foi visto com tanta complexidade, 
e por isso, o item quatro Considerações finais, apenas considera a possibilidade da epistemologia da complexidade fazer parte desse processo, o que parece ter sido um dos principais objetivos da epistemologia desde o seu surgimento.

\section{Abordagens em epistemologia}

Muitos questionamentos existem em torno do termo epistemologia. Esses questionamentos vão desde seus domínios, enquanto disciplina científica (BLANCHÉ, 1983; JAPIASSU, 1986), até seu aparecimento e etimologia (CARRILHO; SÀÁGUA, 1991).

Blanché diz que a epistemologia significa teoria da ciência e não se trata de uma palavra muito antiga. Surge nos dicionários "franceses" por volta de 1906 (BLANCHÉ, 1983, p.9). No entanto, o autor diz que no século XIX já havia obras tratando do tema, inclusive com a palavra epistemologia presente no título (BLANCHÉ, 1983, p.11). Para Japiassu, etimologicamente, epistemologia significa "discurso (logos) sobre a ciência (episteme)" e surge no século XIX (JAPIASSU, 1986, p.24). Não obstante, Carrilho e Sàágua remetem o aparecimento da palavra epistemologia, "em língua francesa", ao ano de 1901. Dizem que a "[...] epistemologia, entendida como filosofia da ciência, surge no século XIX [...]" e creditam o seu aparecimento ao desenvolvimento científico, procurando "[...] explicitar o segredo do seu progresso e legislar sobre o seu valor e objetivos [...]." (CARRILHO; SÀÁGUA, 1991, p.12).

A palavra epistemologia começou a figurar no vocabulário filosófico ${ }^{3}$ a partir do século XIX. Para Santos, a reflexão epistemológica "moderna" origina-se, enquanto filosofia, no "[...] século $X V I I$ e atinge um dos seus pontos altos em fins do século XIX, ou seja, no período que acom- panha a emergência e a consolidação da sociedade industrial e assiste ao desenvolvimento espetacular da ciência e da técnica." (SANTOS, 2000, p.17). Para outros, como Bunge (1980), o campo epistemológico emergiu, para o pensamento contemporâneo, a partir de meados do século XX. Com o próprio desenvolvimento científico e tecnológico surgem estudiosos que, preocupados com esse processo, começam a formular uma teoria epistemológica e a "resgatar" pensadores que já haviam tratado do tema em períodos anteriores.

Para Bunge, a epistemologia, ou "filosofia da ciência", "[...] é o ramo da Filosofia que estuda a investigação científica e seu produto, o conhecimento científico." Considera a epistemologia como importante componente ("ramo") da Filosofia ("árvore") que começa a se destacar nas primeiras décadas do século XX (BUNGE, 1980, p.5). Talvez, em função dessa importância, seja tão difícil conceituá-la, pois, "[...] da epistemologia sabemos muito sobre aquilo que ela não é, e pouco sobre aquilo que é ou se torna [...]", justamente por causa de sua recente emergência enquanto disciplina (JAPIASSU, 1986, p.23). Tal dificuldade também é expressa nas obras de Blanché (1983) e Carrilho e Sàágua; estes últimos referem-se ao termo epistemologia como "nebuloso" (CARRILHO; SÀÁGUA, 1991, p.7).

Assim, a epistemologia pode ser tomada como uma "[...] disciplina, ou tema, ou perspectiva de reflexão cujo estatuto é duvidoso, quer em função do seu objeto, quer em função do seu lugar específico nos saberes." (SANTOS, 2000, p.20). Parece também seguir esta premissa, Japiassu, quando diz que definir epistemologia não é uma tarefa fácil, devido à condição "flutuante" de seus domínios investigativos, não existindo "[...] sequer um acordo quanto à natureza dos problemas que ela deve abordar [...]", além de seu campo de pesquisa ser "[...] imenso, supondo grande intimidade com as

3 Para uma discussão sobre "filosofia-enquanto-epistemologia" ver Rorty (1994, p.144 et seq.). 
ciências, cujo princípio e resultados ela deveria estar em condições de criticar. Donde a variedade de conceitos em epistemologia." (JAPIASSU, 1986, p.23).

Dessa maneira, a epistemologia preocupa-se com as histórias da ciência e da "inteligência", com a "arqueologia" e as "[...] relações da ciência com a sociedade que a produz, interferindo tanto em sua organização interna quanto em suas aplicações." (JAPIASSU, 1986, p.11). Ainda, a epistemologia é a reflexão, o estudo de propósito crítico sobre uma ciência constituída ou, segundo Japiassu (1981), em processo de constituição. Um estudo epistemológico pode visar à discussão de determinados princípios estruturais de uma respectiva disciplina científica. Pode-se dizer que serve para reorganizar ou reencaminhar determinada disciplina ao trajeto científico, ou seja, tenta "delimitar" o campo de estudo dessa disciplina. Por este motivo, a palavra epistemologia é encontrada em dicionários de filosofia como análoga à teoria do conhecimento e gnosiologia (ABBAGNANO, 1982). Pode-se também encontrá-la como a teoria do conhecimento científico. Mora (1994) diz que, por algum tempo, na "língua espanhola", usava-se gnosiologia (teoria do conhecimento) ao invés de epistemologia. A gnosiologia logo passou a significar teoria do conhecimento em seu sentido mais abrangente. À epistemologia coube o estudo do conhecimento científico. Porém, com a influência da filosofia "anglo-saxônica", a epistemologia é cada vez mais usada em "quase todos os casos" e não apenas no campo científico.

Para Japiassu (1986) a epistemologia deve ser entendida como uma disciplina que não se interessa tanto pelos aspectos metodológicos, "os resultados ou a linguagem 'da' ciência, ou da 'razão' nas ciências”. Isto não significa que a espistemologia ignore tais questões, apenas não parecem ser prioritárias em suas investigações. O estudo epsitemológico está relacionado a uma "reflexão crítica" que permite a descoberta e a análise de "[...] problemas tais como eles se colocam ou se omitem, se resolvem ou desaparecem, na prática efetiva dos cientistas". Portanto, o objeto a ser estudado é a práxis científica e não o seu produto, ou seja, a epistemologia à qual se refere Japiassu (1981) tem como função refletir não sobre a "ciência feita, acabada, verdadeira", mas, sobre o processo de desenvolvimento científico (JAPIASSU, 1981, p.96).

Ainda, segundo Japiassu, há uma "flexibilidade" no emprego do conceito epistemologia. Esta flexibilidade depende de vários fatores. Ideologias, filosofias, costumes, culturas, vão determinar se o conceito de epistemologia será de "natureza" filosófica, estando assim, próximo a uma "teoria geral do conhecimento", ou de natureza mais restrita, levantando questões acerca da "gênese e estrutura das ciências". Também podem fazer parte do conceito de epistemologia a "análise lógica da linguagem científica" e o "exame das condições reais de produção dos conhecimentos científicos". Nenhum dos conceitos que possam ser utilizados terão, como princípio, uma imposição dogmática. A dispersão do conceito de epistemologia afasta de vista lingüístico, sociológico, ideológico, etc." Japiassu considera a epistemologia uma ciência interdisciplinar. Portanto, "[...] cabe à epistemologia perguntar-se pelas relações existentes entre a ciência e a sociedade, entre a ciência e as instituições científicas, entre as diversas ciências, etc.". (JAPIASSU, 1986, p.38).

A epistemologia fundamenta-se nos conhecimentos que são produzidos e estão relacionados à ciência. É responsável pelo processo de discernimento entre o conhecimento científico já superado e aquele que se considera atual (JAPIASSU, 1986, p.32). Ou seja, parte dos estudos epistemológicos a iniciativa para a discussão dos paradigmas científicos. Entendida como "teoria do fundamento da ciência", é responsável pela distinção entre objeto científico e objeto da "história das ciências", além da 
manutenção da consciência do real através dos "discursos críticos e progressivos" que se transformam em ciência. É ainda a epistemologia que "[...] faz com que o objeto da história das ciências seja um objeto não dado, mas um objeto construído, um objeto cujo inacabamento é essencial" (JAPIASSU, 1986, p.33). A epistemologia forma-se a partir da reflexão sobre os processos de construção científica de determinada disciplina; portanto, é através do estudo do estatuto científico de tal disciplina que se dá início ao estudo epistemológico.

Para Japiassu existem classificações entre as ciências. Essas classificações são "necessárias" epistemologicamente para tentar identificar relações e diferenças entre as disciplinas científicas. Tal classificação pode criar disparidades como forma de conferir superioridade a determinados grupos científicos sobre outros. "[...] podemos perceber, por detrás de toda classificação, a idéia de uma hierarquia e de uma valorização de certas ciências em detrimento das outras." (JAPIASSU, 1981, p.101).

Nesse sentido, cita as disciplinas ligadas à experimentação e, especificamente, a Física. As Ciências Humanas não seriam reconhecidas no meio científico, pois, neste momento, as Ciências Naturais é que teriam o estatuto científico a seu favor, estando "[...] apoiadas numa valorização por demais excessiva dos métodos e dos resultados das chamadas ciências naturais." (JAPIASSU, 1981, p.103). Entende-se que esta proposição não tira o caráter científico da área de Humanas, pois, a ciência "[...] é um processo histórico dependente, não do ser, mas do devir. E é exatamente por isso que não temos o direito de negar às Ciências Humanas sua existência e sua legitimidade." (JAPIASSU, 1981, p.104). Aepistemologia chega a apresentar, realmente, em determinados contextos, um caráter ambíguo, podendo ser considerada falsa e até como uma ilusão, porém, torna-se "[...] verdadeira na sua falsidade" e se transfigura em uma "ilusão necessária" (SANTOS, 2000, p.27).

A epistemologia, por estar relacionada às disciplinas científicas, não pode ter uma definição ou conceito que a enquadre em um campo específico do conhecimento ou que a vincule a uma única disciplina, pois uma de suas principais características enquanto disciplina científica, segundo Japiassu (1986), é a interdisciplinaridade. Para Blanché, a epistemologia não depende do que é "verdadeiro ou falso", mas, de um estado de "conveniência". Ao se chegar a este "estado", tem-se o "domínio" epistemológico delimitado, porém, "[...] as fronteiras traçadas permanecerão móveis, porque os problemas da epistemologia abrangem muitas vezes domínios situados para lá dessas fronteiras." (BLANCHÉ, 1983, p.17).

Japiassu (1986) não restringe o campo de atuação epistemológica à filosofia ou à sociologia da ciência, pelo contrário, aborda esse campo de atuação da maneira mais abrangente possível, considerando, entre outras características, leis, costumes, ideologias, filosofias, aspectos lingüísticos e pragmáticos, além de influências históricas e políticas. Cabe, pois, considerar a epistemologia como uma epistemologia complexa.

O pensamento epistemológico é polêmico. Existem tipos de epistemologias. Elas não se diferenciam apenas pelo objeto que estudam, mas por vários fatores. O modo de abordagem, o contexto do objeto e do observador e as especificidades do objeto acrescidas da interpretação do observador, são os principais aspectos que podem condicionar as diferentes abordagens epistemológicas. A não diferenciação do objeto não significa que o desenvolvimento científico deve ser visto como estacionário.

A constante movimentação do "universo" científico é compreendida como um conjunto de eventos em múltiplas relações. Às epistemologias cabe a consciência desse conjunto de eventos científicos, ao mesmo tempo único e 
múltiplo.. Partindo-se dessa concepção, as abordagens são transformadas de acordo com os contextos relacionais e com a parcialidade observacional (ideologias, filosofias e culturas). Dessa maneira, surge o que se conhece como a epistemologia genética de Jean Piaget, a epistemologia histórica de Gaston Bachelard, a epistemologia "racionalista crítica" de Karl Popper e a epistemologia "arqueológica" de Michel Foucault (JAPIASSU, 1986).

Finalmente, é necessário interrogar-se sobre o conhecimento, sobre o saber, sobre a ciência, sobre o pensamento, de forma geral e específica ao mesmo tempo. Essas interrogações podem ser interpretadas de várias maneiras, dependendo de onde, de como e por quem estão sendo observadas. Podem tanto estar sendo observadas desde a perspectiva do observador, como desde o interior de uma disciplina, como até desde ambas ou nenhuma dessas perspectivas, ou ainda, como se verá na epistemologia da complexidade, desde a perspectiva de todos e desde nenhuma ao mesmo tempo.

\section{Bachelard, Morin e a epistemologia da complexidade}

A epistemologia da complexidade tem suas raízes, segundo Edgar Morin, no pensamento epistemológico de Gaston Bachelard. "[...] houve um filósofo que falou da complexidade e, na minha opinião, muito profundamente: foi Gaston Bachelard em O Novo Espírito Científico." (MORIN, 1996, p.13).

A complexidade essencial da filosofia científica, é o título da introdução de O Novo Espírito Científico. Em alguns trechos dessa obra, o autor deixa claro a sua idéia de filosofia da ciência: "[...] não há nem realismo nem racionalismo absolutos [...]", nem preceitos filosóficos universais e únicos (BACHELARD, 1978, p.91). Dessa maneira, o que propõe Bachelard é um estudo sobre o (espírito) pensamento científico contemporâneo que, distanciando-se do "agnosticismo positivista" e do "realismo filosófico tradicional", aproxime-se "[...] dum realismo de segunda posição, dum realismo em reação contra a realidade habitual, de razão experimentada." E prossegue: "[...] o real que lhe corresponde não é relegado ao domínio da coisa em si incognoscível." (BACHELARD, 1978, p.93). Essa realidade cognoscível é formada e desenvolve-se a partir e através das relações de complexidade. Tais relações se estendem há séculos, como o "diálogo entre o Mundo e o Espírito" e não se pode mais ignorá-las ou caracterizá-las como "experiências mudas". A abordagem das relações entre a realidade e a racionalidade, entre o "Mundo e o Espírito" conduz, inevitavelmente, a pensar a complexidade que envolve essas relações.

Isso se verifica através do próprio pensar a "ação científica", em que "[...] percebe-se que o realismo e o racionalismo permutam sem fim seus pareceres." (BACHELARD, 1978, p.95). Não se prevê um fim. A idéia de finitude associase à imobilidade. A complexidade apenas existe porque os sistemas que a compõem nunca param, estão em constante movimentação, interna e externa, em processos de relações e inter-relações. "Assim, parece-nos que se devem introduzir na filosofia científica contemporânea princípios epistemológicos verdadeiramente novos." (BACHELARD, 1978, p.98).

Há a necessidade de uma epistemologia que se disponha a estudar a "[...] síntese mais ou menos móvel da razão e da experiência mesmo que esta síntese se apresente filosoficamente como um problema desesperado." (BACHELARD, 1978, p.98). Assim como a noção de simplificação torna-se insuficiente e inconsistente em sua redução, a relação entre extremos é quase obrigatória, pois, "[...] o pensamento científico contemporâneo permanentemente opera entre o a priori e o a posteriori [...]." Esses eventos movimentam-se e alternam- 
-se constantemente e "[...] estão ligados, no pensamento científico, por um estranho laço, tão forte como o que une o prazer à dor." (BACHELARD, 1991, p.9). O que autor quer dizer com o a priori e o a posteriori são as maneiras como os cientistas e os filósofos se utilizam do, ou concebem o, pensamento científico: os primeiros, reduzindo a filosofia das ciências aos fatos; os segundos, descartando a possibilidade de a filosofia da ciência relacionar-se aos fatos. Portanto, a idéia do a priori e do a posteriori aproxima-se das noções de determinismo e indeterminismo propostas por Bachelard (1978).

Para Bachelard, "[...] todas as revoluções frutuosas do pensamento científico são crises que obrigam a uma reclassificação profunda do realismo." Porém, essas crises "frutuosas" não são produzidas (provocadas) pelo pensamento realista; o "[...] impulso revolucionário vem de outra parte; nasce no reino do abstrato." (BACHELARD, 1978, p.157).

Independência e relação, determinismo e indeterminismo, a priori e a posteriori em suas relações e inter-relações, infinito e indefinição, e o princípio da incerteza, são alguns dos pontos observados por Bachelard no pensamento científico, os quais fazem dele, segundo Edgar Morin, um dos filósofos da ciência que "falou" da complexidade com maior profundidade. Por outro lado, pode-se dizer que foi através de Edgar Morin que o pensamento complexo se desenvolveu.

Morin (1996) chama a atenção para a seguinte questão: o complexo não é o mesmo que o complicado. Portanto, a epistemologia da complexidade não pode ser entendida como uma epistemologia da complicação, uma epistemologia da dificuldade.

A complexidade moriniana não traz em si complicadores, pelo contrário, traz a possibilidade de pensar o ser em si, sua relação com o mundo, as relações do mundo com o mundo e do ser com o ser. Nesse caso, a epistemologia proposta por Morin é uma epistemologia aberta, sem um princípio rígido norteador. Esta, parte dos eventos do conhecimento, para estudar o próprio conhecimento: o conhecimento do conhecimento. É a partir do conhecimento do conhecimento que se constitui a epistemologia da complexidade, um conhecimento que pensa e conhece os limites do próprio conhecimento. Para Morin (1997), o conhecimento não reflete o "mundo objetivo", mas o traduz e o constrói, dado que a produção, a reprodução e o desenvolvimento do conhecimento fazem parte de um constante construir-desconstruir-construir no universo do próprio conhecimento. Não há imparcialidade e, muito menos, neutralidade nesse processo. A construção, a desconstrução, a reprodução e o desenvolvimento do conhecimento estão "impregnados" pelo conhecimento do observador que os concebe. "Não há conhecimento sem autoconhecimento." (MORIN, 1997, p.201).

A previsão de ruptura está implícita no conhecimento. Acontece que os movimentos de ruptura se dão no mesmo instante em que ocorrem os movimentos de relação. A relação desses eventos se dá em função dos movimentos que relacionam e estão relacionados ao conhecimento. A liberdade de conhecer é o limite do conhecimento. Assim, o conhecimento se condiciona, se determina e se limita pelo não-condicionamento, pelo indeterminismo e pela condição ilimitada em sua gênese, que é justamente o seu limite. O ilimitado, o indeterminismo, o incondicionável e o infinito são o que Morin (1997) chama de as "fontes de incerteza". São essas fontes de incerteza que, enquanto dão origem a uma epistemologia complexa, a partir dela se originam. É nas questões relativas às incertezas que permeiam o conhecimento em sua formação, desenvolvimento ou gênese, que se desenvolve a epistemologia da complexidade. A epistemologia da complexidade não se restringe aos limites do determinismo e do reducionismo que se processam por vias certas, mutiladoras e simplificadas. A proposta de Edgar Morin para 
uma epistemologia complexa é que esta busque não apenas através do possível, mas do impossível, as relações mais profundas do conhecimento do conhecimento, mesmo que essas relações não possam ser conhecidas. O processo que permite conhecer o que é desconhecido em tais relações de conhecimento faz parte da epistemologia da complexidade.

A epistemologia da complexidade vê complementaridade nos antagonismos, ou seja, a relação e a complementação mútua de posições opostas ou contrárias, sendo ao mesmo tempo a disciplina que engloba e é englobada pelo objeto sem, necessariamente, isolar ou estar isolada. Nesse caso, a epistemologia complexa "[...] terá uma competência mais vasta que a epistemologia clássica, sem todavia dispor de fundamento, de lugar privilegiado, nem de poder unilateral de controle." (MORIN, 1999, p.31). O autor reúne em sua epistemologia complexa as epistemologias bachelardiana e piagetiana. A epistemologia histórica e filosófica de Bachelard é chamada por Morin de "complexa" e a epistemologia genética de Piaget é tratada como "[...] a biologia do conhecimento, a articulação entre lógica e psicologia, o sujeito epistêmico." (MORIN, 1999, p.31). Uma epistemologia desse tipo transcende a concepção apenas científica ou filosófica do conhecimento. Lança uma multiplicidade de abordagens epistemológicas que, além de "contemplar" os aspectos biológicos, sociais, culturais e psicológicos, os relaciona. Essa abordagem propõe a análise dos "instrumentos" de produção do conhecimento, ou seja, os instrumentos neurocerebrais.

A complexidade e a epistemologia que a representa são fundamentais para se estudar e pensar o pensamento, o conhecimento e o próprio desenvolvimento científico, seja através de uma filosofia, de uma sociologia ou de uma teoria científica, desde que não redutora e determinista. São características difíceis - quase impossíveis - de serem captadas ou incorporadas ao processo de desenvolvimento científico em si, mas viáveis e necessárias ao pensamento que pensa esse processo.

Edgar Morin não traz idéias prontas, nem mesmo possui, como ele mesmo diz, um paradigma em seu "bolso". Não se deve entender o pensamento complexo como uma via de mão única, sistêmica, totalizante e/ou suficiente em si mesma. A idéia de complexidade não é uma via de mão única, "[...] ela contém em si a impossibilidade de unificar, a impossibilidade de acabamento, uma parte de incerteza, uma parte de indecisibilidade e o reconhecimento do tête-à-tête final com o indizível." (MORIN, 1996, p.98).

O pensamento complexo é uma grande contribuição dada, por Edgar Morin, ao próprio pensamento. Mesmo não sendo ele o precursor da complexidade, foi quem mais a desenvolveu. A maior parte de sua obra está baseada no pensamento complexo. Morin considera como um dos eventos fundamentais para a complexidade a própria informação. A informação é um dos eventos primeiros na constituição da vida e do cosmos (MORIN, 2002a), isto é, a informação está na origem da vida, em sua gênese, onde gera-se, regenera-se, auto-regenera-se e se auto-organiza. Passa, dessas relações de informações "genésicas" às relações da vida (MORIN, 2001), às relações do conhecimento (MORIN, 1999), às relações das idéias (MORIN, 1998) e às relações humanas (MORIN, 2002b). Todas essas relações são relações de complexidade.

\section{CONSIDERAÇÕ ES FINAIS}

Os percursos e as discussões descritos neste texto tiveram como uma de suas principais funções tentar evidenciar uma epistemologia relacionada e distintiva (não separativa) como condição a uma epistemologia complexa. Isso pode parecer confuso e redundante diante de um olhar apressado. Por outro lado, a redundância aparente do discurso da complexidade traz, na realidade, um tom renovador. É a repetição que 
não exclui, porém, renova. A epistemologia da complexidade confia, de certa maneira, no olhar do outro. Parte desse para constituir-se como metodologia. Isso significa comportar, em seus processos e procedimentos, jogos de racionalidade promovidos pela presença e pela ausência do ser enquanto ser consciente. Aspectos da mente ou self ou, especificamente, da própria cognição, parecem renovar as abordagens sobre a informação. Neste caso, os padrões metodológicos se repetem a partir de perspectivas distintas. O novo apenas é novo se partir do que é antigo.

\section{REFERÊ N CIAS}

ABBAGNANO, N. Dicionário de filosofia. 2.ed. São Paulo: Editora Mestre Jou, 1982.

BACHELARD, G. A filosofia do não: filosofia do novo espírito científico. Lisboa: Editorial Presença, 1991.

BACHELARD, G. O novo espírito científico. São Paulo: Abril Cultural, 1978. (Os Pensadores).

BLANCHÉ, R. A epistemologia. 3.ed. Lisboa: Editorial Presença, 1983.

BUNGE, M. Epistemologia: curso de atualização. São Paulo: USP, 1980.

CARRILHO, M.M.; SÀÁGUA, J. Epistemologia: posições e críticas. Lisboa: Fundação Calouste Gulbenkian, 1991.

JAPIASSU, H. Introdução ao pensamento epistemológico. 4.ed. Rio de Janeiro: Francisco Alves Editora, 1986.

JAPIASSU, H. Questões epistemológicas. Rio de Janeiro: Imago, 1981.

MORA, J.F. Diccionario de filosofía. Barcelona: Editorial Ariel, 1994.
A epistemologia da complexidade aparece em função dessas distinções de perspectivas, ou seja, o pensamento que pensa um objeto não subestima a capacidade de re-criar o próprio objeto. Não há soberania nesse processo, pois, não se pode identificar como e quando isso ocorre, visto a necessidade de uma consciência possível.

Portanto, uma proposta reiterada é uma proposta nova. A necessidade de respeitar os limites do conhecimento pressupõe também conhecer o que há além desses limites. Conhecer a partir do mesmo é uma das formas mais elevadas de conhecimento.

MORIN, E. O problema epistemológico da complexidade. 2.ed. Portugal: Europa-América, 1996.

MORIN, E. Meus demônios. Rio de Janeiro: Bertrand Brasil, 1997.

MORIN, E. O método 4: as idéias. Habitat, vida, costumes, organização. Porto Alegre: Sulina, 1998.

MORIN, E. O método 3: o conhecimento do conhecimento. Porto Alegre: Sulina, 1999.

MORIN, E. O método 2: a vida da vida. Porto Alegre: Sulina, 2001.

MORIN, E. O método 1: a natureza da natureza. Porto Alegre: Sulina, 2002a.

MORIN, E. O método 5: a humanidade da humanidade. Porto Alegre: Sulina, 2002b.

RORTY, R. A filosofia e o espelho da natureza. Rio de Janeiro: Relume-Dumará, 1994.

SANTOS, B.S. Introdução a uma ciência pós-moderna. 3.ed. Rio de Janeiro: Graal, 2000. 
